\title{
Wavelength dependence of aerosol optical thickness in the UV-B band
}

\author{
V. W. J. H. Kirchhoff \\ Instituto Nacional de Pesquisas Espaciais, São José dos Campos, Brasil
}

\author{
A. A. Silva \\ Pontifícia Universidade Católica de Minas Gerais, Belo Horizonte, Brasil \\ D. K. Pinheiro \\ Universidade Federal de Santa Maria, DTPI/LACESM, Santa Maria, Brasil
}

Received 27 September 2001; revised 16 March 2002; accepted 17 March 2002; published 29 June 2002.

[1] The optical thickness of the atmosphere, $\tau_{a t}$, was deduced from measurements of narrowband direct solar UV-B $(280-320 \mathrm{~nm})$ radiation. This is the radiation that is strongly absorbed in the stratosphere by ozone, especially near the lower limit wavelength of these measurements, $306.3 \mathrm{~nm}$. Measurement campaigns were organized to obtain radiation data at different sites, for different kinds of aerosol, using the same methods and instruments, in order to deduce the atmospheric optical thickness for different atmospheric conditions. The measurements were made with a Brewer spectrophotometer at each site. This instrument measures also the atmospheric ozone and sulphur dioxide columns, and therefore it is possible to deduce the aerosol optical thickness, $\tau_{a e}$. The possibility of additional absorptions in the UV-B band, especially formaldehydes, is investigated. Two data sets are examined: C. Grande and S. Paulo. A large percentage of the data show that the wavelength dependence of the aerosol optical thickness is one that appears to increase with wavelength. In other words, the difference between the absolute values at 320.1 and 306.3 $\mathrm{nm}$, is positive for the majority of cases. However, this difference is not always larger than the uncertainty/error of the measurement. This intriguing result opposes the Angstrom law, applicable to a much larger dynamic range in wavelength. For the C. Grande data (with generally larger values of optical thickness), the difference is positive in 16 out of 19 cases, but there are only 4 cases when the difference is larger than the error. For the S. Paulo morning data, however, the opposite is true. The difference is positive with only one exception, and there are 13 cases out of 17 where the difference is larger than the error. INDEX TERMS: 0305 Atmospheric Composition and Structure: Aerosols and particles $(0345,4801)$; 0345 Atmospheric Composition and Structure: Pollution - urban and regional (0305); 0365 Atmospheric Composition and Structure: Troposphere-composition and chemistry

\section{Introduction}

\subsection{Characteristics of the UV-B Spectral Band}

[2] A small portion of the solar radiation spectrum, extending from 280 to 320 nanometers $(\mathrm{nm})$, is known as the UV-B band. This radiation is invisible to the human eye, and has health damaging properties, being responsible for human skin cancer, for example [Urbach, 1969]. The most important feature of this narrowband radiation is that it is absorbed by ozone in the stratosphere [Stolarski, 1988]. With the continuing process of

Copyright 2002 by the American Geophysical Union. 0094-8276/02/2001GL014141 ozone depletion in the stratosphere, more of this radiation will be able to penetrate the troposphere, and thus participate in chemical reactions and aerosol scattering. In general, instruments that are used for optical thickness measurements in the visible are inadequate for measurements in the UV-B. Ross et al. [1997, 1998] and Eck et al. [1999] obtained aerosol optical thickness $\tau_{a e}$ information in the visible region of the spectrum, from 340 to $1020 \mathrm{~nm}$, during the Smoke, Clouds and Radiation-Brazil (SCAR-B) field campaign of 1995, which took place in the cerrado region in Brazil [Kaufman et al., 1998; King et al., 1998]. The Ross et al. data have been obtained with a sunphotometer [Holben et al., 1996].

[3] The present data set was obtained with an optimized procedure for the acquisition of direct solar UV-B radiation with a Brewer spectrophotometer [Brewer, 1973], deducing the optical thickness of the atmosphere, $\tau_{a t}$ by the Langley method.

\subsection{Instruments and Methods}

[4] One concern in the extreme UV-B measurements of the Brewer relates to stray light effects. The single monochromator Brewer spectrophotometer, used in this work, is subject to stray light effects below about $300 \mathrm{~nm}$. In an experiment conducted using a single laser monochromatic light source this could be measured [Fioletov et al., 2000]. In our measurements, we do not use wavelengths below $306.3 \mathrm{~nm}$. The data was obtained at different sites, in order to sample different kinds of aerosols, as described in Kirchhoff et al. [2001]. The sites used the same instruments and methods to obtain $\tau_{a t}$.

\section{Results and Discussion}

[5] A special field experiment described in Kirchhoff et al. [2001], obtained data at 3 different sites: a marine site, a high altitude site and a biomass burning site; results of an additional field experiment are added here, which measured the aerosol optical thickness in the city of S. Paulo, Brazil, (23.55 S; $46.73 \mathrm{~W})$ in order to sample pollution type aerosols, in the UV-B band. The absolute values of optical thicknesses have been determined in the UV-B spectral range, from regions of relatively clean air to a region of considerable biomass burning activity. Absolute values for $\tau_{a t}$ in relatively clean air were near 2.0 and in biomass burning regions, between 2.5 and 3.0, but with occasional highs of about 4.5. For $\tau_{a e}$ in clean air, values between 0.0 and 0.4 were found, whereas in biomass burning areas most values were near 0.4 , with occasional highs near 1.0, 1.2 and 2.2.

\subsection{Comparison with Satellite Data}

[6] The extrapolated Brewer data compare well with the Atlas 3 satellite data series. [Kaye and Miller, 1996; Cebula et al., 1996]. 


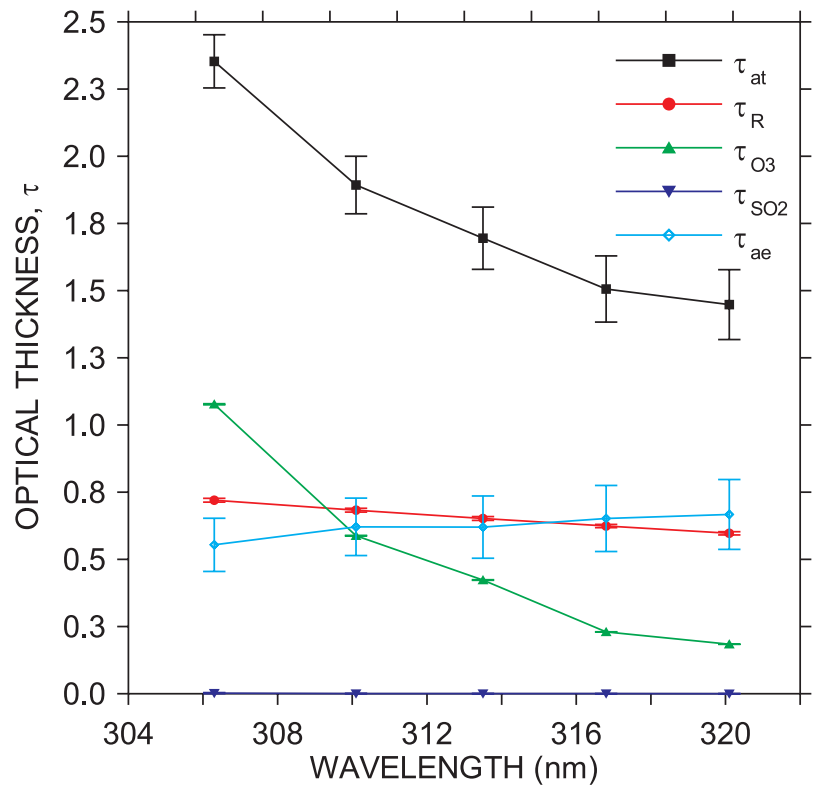

TauaLP.grf

Figure 1. Comparison of the atmospheric thickness components of $\tau_{a t}$ for data obtained at La Paz, for Julian day 232, afternoon.

\subsection{Typical Optical Depth Values}

[7] Typical optical depth parameters are shown as an example in Figure 1. The optical depth for $\mathrm{SO}_{2}$ is negligible at all wavelengths in this case, and is shown at the very bottom of the figure. Here the data for the La Paz site are used, as observed on August 20, 1999 (Julian day 232). The atmospheric optical depth $\tau_{a t}$ is the one obtained by the Langley method. The figure shows that Rayleigh scattering is of the same order of magnitude of the aerosol optical thickness, at the different wavelengths. At the short extreme of $306.3 \mathrm{~nm}, \tau_{O 3}$ starts to dominate the other terms. The aerosol

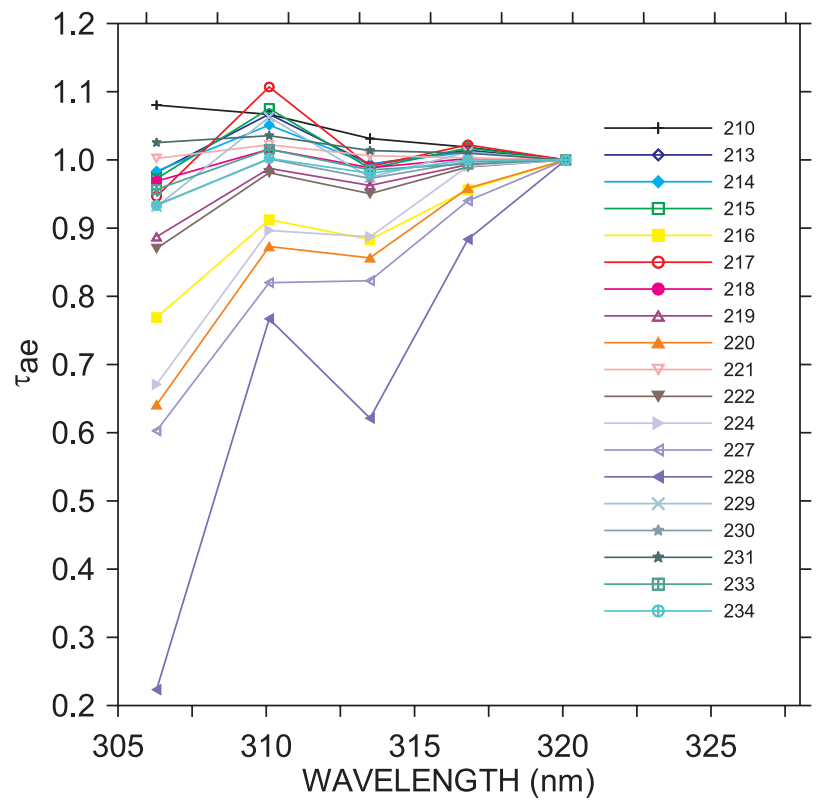

TaeCg99aN.grf

Figure 2. The variations of $\tau_{a e}$ with wavelength in the UV-B band. Data obtained for Campo Grande, afternoons. Values are normalized at $320.1 \mathrm{~nm}$.

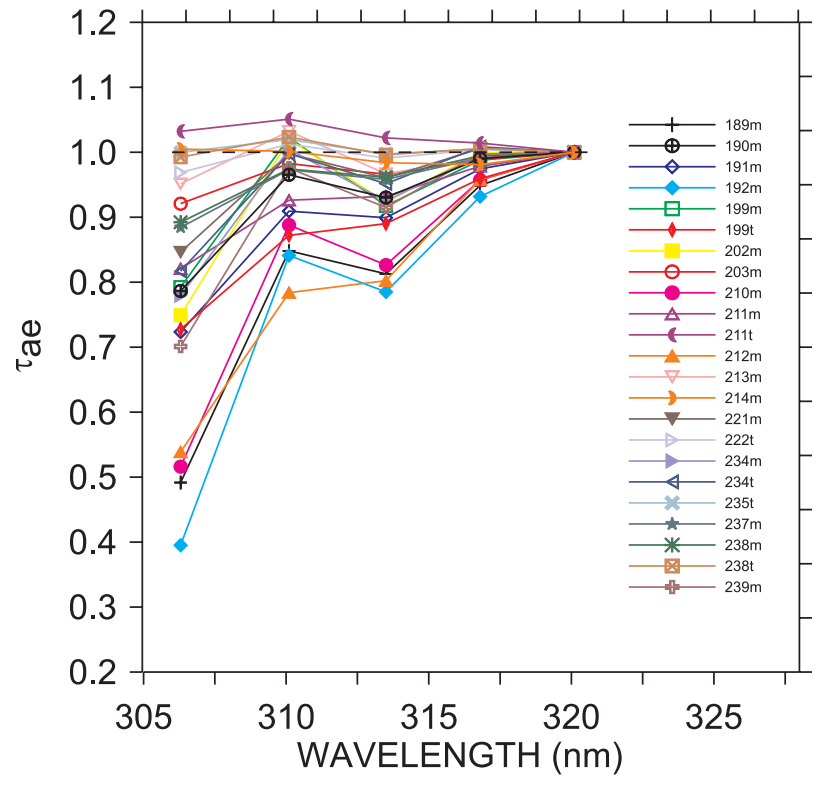

AEROSOISX

Figure 3. The variations of $\tau_{a e}(\mathrm{~m}-$ morning, $\mathrm{t}-$ afternoon) with wavelength in the UV-B band, for measurements in the downtown area of S. Paulo city. Values are normalized at $320.1 \mathrm{~nm}$.

component $\tau_{a e}$ is the smallest at $306.3 \mathrm{~nm}$. At $320 \mathrm{~nm} \tau_{O 3}$ is the smallest, and at 306.3 it is the largest.

\subsection{Variations of $\tau_{a e}$ with Wavelength}

[8] The wavelength dependence of $\tau_{a e}$ over a wide range in the visible, from 400 to $700 \mathrm{~nm}$, is such that it increases with decreasing wavelength according to a $\lambda^{-\alpha}$ law (sometimes called the Angstrom law), where $\lambda$ is the wavelength and $\alpha$ is a constant [Angstrom, 1964]. Ross et al. [1997, 1998] have measured $\tau_{a e}$ values from absolute magnitudes of about 0.5 to 1.5 , which approximately follow the theoretical $\lambda^{-\alpha}$ law.

[9] In the UV-B range the present data suggest that the wavelength dependence is different. The data for the Campo Grande site show that $\tau_{a e}$ near the lower wavelength end has absolute values that are consistently the smallest in the band. In order to consider only the wavelength dependence and not the absolute values, the data points were normalized to unity at $320.1 \mathrm{~nm}$. This is shown in Figure 2, for the Campo Grande site. For the La Paz and Natal data the behavior is similar. In the S. Paulo experiment, where big city pollution aerosols were sampled, the results were again similar to the other 3 sites. As shown in Figure 3, the S. Paulo data also show a distinct tendency to increase with wavelength. Day numbers are shown for morning $(\mathrm{m})$ and afternoon $(\mathrm{t})$ periods. An error propagation analysis is shown in the Appendix. As can be seen in the examples of Table A1, the uncertainty/errors of the measurement are relatively small compared to the absolute value of the optical thickness. Table A2 shows the differences between the absolute values of the aerosol optical thickness at 320.1 and $306.3 \mathrm{~nm}$, and the measurement error, for the S. Paulo morning observations.

[10] It is interesting to note that Marenco et al. [1997], have described measurements that also showed lower extinction values at the lower wavelength extreme, but lacking a better explanation, believed this was caused by large measurement errors in their experiment. It should be noted, that the present data have signal to noise ratios that are much higher than those of Marenco et al. Since different instruments were used in the present experiments, it can be said that this feature is not instrument dependent, neither a specific site (aerosol type) effect. Also, as mentioned before, it seems not to be a stray light effect. 
Table A1. Optical Thickness and Uncertainties at $306.3 \mathrm{~nm}$. Examples for the 1999 Campo Grande Campaign

\begin{tabular}{cccccc}
\hline $\mathrm{JD}$ & $\tau_{a t} \pm \delta_{a t}$ & $\tau_{O 3} \pm \delta_{O 3}$ & $\tau_{S O 2} \pm \delta_{S O 2}$ & $\tau_{R} \pm \delta_{R}$ & $\tau_{a e} \pm \delta_{a e}$ \\
\hline 215 & $2.64 \pm 0.03$ & $1.19 \pm 0.01$ & $0.01 \pm 0.01$ & $1.05 \pm 0.01$ & $0.39 \pm 0.04$ \\
219 & $2.88 \pm 0.27$ & $1.16 \pm 0.01$ & $0.04 \pm 0.01$ & $1.05 \pm 0.01$ & $0.64 \pm 0.27$ \\
230 & $2.94 \pm 0.11$ & $1.17 \pm 0.01$ & $0.01 \pm 0.01$ & $1.05 \pm 0.01$ & $0.72 \pm 0.11$ \\
\hline
\end{tabular}

[11] Note that the Angstrom law has been shown to be valid over large wavelength intervals, when $\alpha$ is a small positive value. We have already mentioned the results of Ross et al. [1997]. Variations that increase with $\lambda$, or in other words, those with a negative $\alpha$ have in fact been observed over small wavelength bands by several authors. For example, Cachorro et al. [1996] report optical thicknesses over the range from 350 to $700 \mathrm{~nm}$, over which there is a reasonable average fit to the Angstrom law, with $\tau_{a e}$ decreasing with wavelength. However, inversions occur in smaller bands, for example, between 580 and $630 \mathrm{~nm}$, where $\tau_{a e}$ increases with wavelength. Again, negative $\alpha$ values are also reported in short bands by Jacovides et al. [2000], and by Cachorro et al. [1989], who present negative values over small ranges and even over large ones (from 450 to $650 \mathrm{~nm}$ ). In another case reported by Bridgman [1978], a negative $\alpha$ was found in the range from 450 to $710 \mathrm{~nm}$.

\subsection{Effects of Other Trace Gases on $\tau_{a e}$}

[12] The aerosol optical thickness $\tau_{a e}$, as deduced in this paper, may be overestimated if there are other trace gases absorbing UV-B radiation, and this may affect the observed wavelength dependence. A systematic additional absorption situation could in this case be inserted into the Brewer spectrophotometer data analysis algorithm and be explored to the point where another atmospheric constituent could be measured routinely by the observation system. This possibility is investigated in this section.

[13] Figure 4 shows typical optical thicknesses at $310 \mathrm{~nm}$ for ozone $\left(\mathrm{O}_{3}\right)$, sulphur dioxide $\left(\mathrm{SO}_{2}\right)$, formaldehyde $(\mathrm{HCHO})$, acetaldehyde $\left(\mathrm{CH}_{3} \mathrm{CHO}\right)$, propionaldehyde $\left(\mathrm{C}_{2} \mathrm{H}_{5} \mathrm{CHO}\right)$, and nitrous acid (HONO) for reasonable ranges of atmospheric abundances, according to the references shown below. The aerosol optical thickness is shown in the figure as a small shaded area near a value of 0.5 . Minimum and maximum values are also indicated, on the basis of the present measurements. Ozone is the most important trace gas for UV-B absorption. Then comes $\mathrm{SO}_{2}, \mathrm{H}_{2} \mathrm{CO}$, and the

Table A2. $\tau_{a e}$, Uncertainties at 306.3 and $320.1 \mathrm{~nm}$, and Differences Between these Two for Morning Data of the $2000 \mathrm{~S}$. Paulo Campaign

\begin{tabular}{cccc}
\hline $\mathrm{JD}$ & $\tau_{a e 306.3} \pm \delta_{a e 306.3}$ & $\tau_{a e 320.1} \pm \delta_{a e 320.1}$ & $\tau_{a e 320.1}-\tau_{a e 306.3}$ \\
\hline 189 & $0.10 \pm 0.04$ & $0.20 \pm 0.04$ & 0.10 \\
190 & $0.30 \pm 0.06$ & $0.39 \pm 0.07$ & 0.08 \\
191 & $0.25 \pm 0.04$ & $0.35 \pm 0.03$ & 0.10 \\
192 & $0.07 \pm 0.08$ & $0.17 \pm 0.09$ & 0.10 \\
199 & $0.20 \pm 0.03$ & $0.25 \pm 0.03$ & 0.05 \\
202 & $0.18 \pm 0.08$ & $0.23 \pm 0.08$ & 0.06 \\
203 & $0.86 \pm 0.09$ & $0.93 \pm 0.08$ & 0.07 \\
210 & $0.11 \pm 0.05$ & $0.21 \pm 0.05$ & 0.10 \\
211 & $0.72 \pm 0.08$ & $0.87 \pm 0.07$ & 0.16 \\
212 & $0.16 \pm 0.09$ & $0.29 \pm 0.09$ & 0.14 \\
213 & $0.42 \pm 0.03$ & $0.45 \pm 0.03$ & 0.02 \\
214 & $0.99 \pm 0.13$ & $0.99 \pm 0.13$ & -0.00 \\
221 & $0.44 \pm 0.06$ & $0.51 \pm 0.06$ & 0.08 \\
234 & $0.22 \pm 0.04$ & $0.28 \pm 0.03$ & 0.06 \\
237 & $0.75 \pm 0.06$ & $0.85 \pm 0.06$ & 0.10 \\
238 & $0.83 \pm 0.10$ & $0.93 \pm 0.10$ & 0.10 \\
239 & $0.21 \pm 0.05$ & $0.30 \pm 0.04$ & 0.09 \\
\hline
\end{tabular}

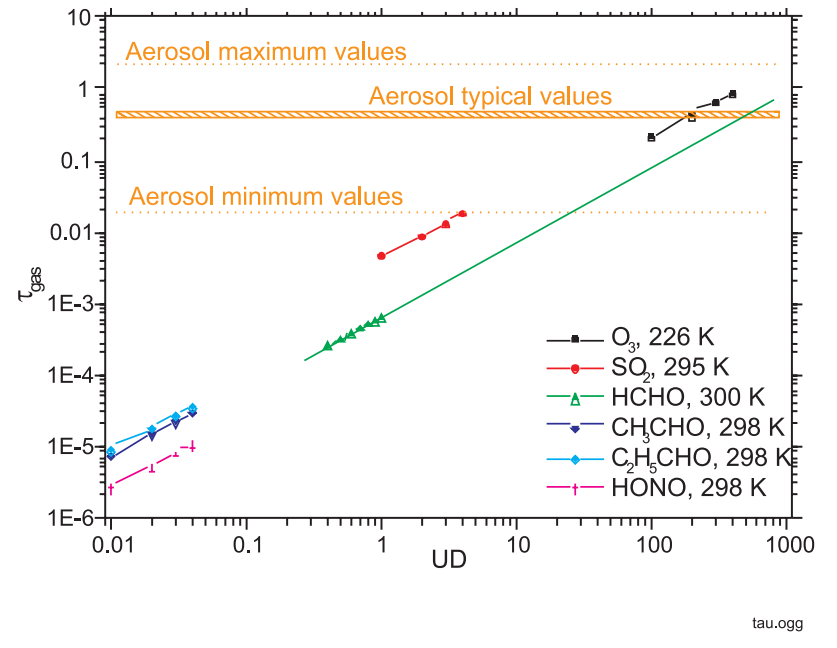

Figure 4. Comparison of ranges of optical thickness values for different gases as a function of gas abundance in the atmosphere, at $310 \mathrm{~nm}$.

remaining components shown in the figure. Although sulphur dioxide has a slightly larger absorption cross section than ozone in the UV-B range [Molina and Molina, 1986; McGee and Burris $J r$. 1987], the usual atmospheric abundance is so small (about 1 Dobson unit) that it can be neglected [Levine, 1985]. Aldehydes, and nitrous acid, have even lower absorption cross sections and low abundances [Levine, 1985; Pitts and Pitts Jr., 1986; Seinfeld, 1986; Warneck, 1988] and thus, optical thicknesses are lower than those for $\mathrm{SO}_{2}$. This result is valid for all wavelengths of the UV-B range. Note that expected atmospheric abundances at non polluted sites are assumed, according to above references, but evidently in some special situation the abundances could be higher. Nevertheless, in order to become a significant fraction of the optical thickness, the abundance for formaldehyde would have to increase by at least two orders of magnitude, which seems unlikely. Recent aircraft observations [Lee et al., 1998] show maximum low altitude concentrations of formaldehyde of about $12 \mathrm{ppbv}$, which decrease to about 4 ppbv at $2 \mathrm{~km}$ height; and Palmer et al. [2001] also show observations with maximum concentrations of $4 \mathrm{ppbv}$ and a mixing layer height of about $2 \mathrm{~km}$, which corresponds to the situation depicted in Figure 4. In case of a heavily polluted site, the formaldehyde concentration (abundance) could increase significantly, but then so would the aerosol concentration (abundance) as well, and the proportion in the figure would be similar. Thus, within the conditions analyzed in this paper, aldehydes do not influence the method of deducing the aerosol optical thickness.

\section{Conclusions}

[14] A comprehensive unique data set was obtained to deduce optical depths, in the UV-B band. From Brewer spectrophotometer measurements of the atmospheric optical thickness, it is possible to calculate the aerosol optical thickness in the UV-B spectral band. Measurements were made using the same type of instrumentation (Brewer MKIV) and technique at different sites, in order to sample different environments. From this data set, in summary, the results are as follows:

1. From the data sets collected in S. Paulo and C. Grande, the majority of observations show that the difference of aerosol optical thickness between 320.1 and $306.3 \mathrm{~nm}$ is positive (indicating an increase with wavelength). We have not obtained any data set in which negative differences prevail. What remains to be seen is whether this difference is statistically significant. For the present data sets, it was significant for the S. Paulo data set. From the total 17 cases of morning observations, 16 had positive differences, and 
13 had differences larger than the uncertainty/error of the measurement (see Table A2). The results are less significant for the C. Grande data set, where the difference was positive in 16 out of 19 cases; but the difference was larger than the error of the measurements in only 4 cases (from the total of 19).

2. This behavior is the same at different sites, under different environmental conditions, that is, with large or small particle concentrations, and different kinds of aerosol. It is instrument independent, since a different instrument was used at each site, and it does not appear to be a stray light effect, which has been observed with Brewer measurements only at wavelengths lower than $300 \mathrm{~nm}$.

\section{Appendix A: Error Propagation Analysis}

[15] The uncertainty of the aerosol optical thickness can be written as the square root of the sum of the squares of the components. While the gaseous optical thickness is the product of abundance in the atmosphere and the absorption cross section, the uncertainty of the gas components can be written,

$$
\delta_{\text {gas }}=2.69 E 16\left[\left(N \delta_{\sigma}\right)^{2}+\left(\sigma \delta_{N}\right)^{2}\right]^{0.5}
$$

where $\delta_{\sigma}$ and $\delta_{N}$ are the $\sigma$ and $\mathrm{N}$ uncertainties, respectively. $\delta_{R}$ is assumed to be equal to $1 \%$ of the Rayleigh optical thickness as suggested by Teillet [1990]. Nominal values obtained from equation (A1), for a few cases, are given in Table A1 and Figure 1.

[16] Acknowledgments. The possibility of measuring formaldehydes with the Brewer spectrophotometer was suggested by Wayne Evans. We are grateful to José Roberto Chagas for the field work at EMPAER, in Campo Grande, MS, during the month of August 1999. For coordination of the work at Natal, we thank Francisco da Silva, and at La Paz we thank Francesco Zaratti. Financial support from INPE (basic infrastructure), EMPAER (infrastructure in CG), CAPES (scholarship for AAS) and FAPESP (several grants) are acknowledged. We also thank the Ozone Lab staff for their support. The international calibration of the Brewer spectrophotometers has been made by Ken Lamb.

\section{References}

Angstrom, A., The parameters of atmospheric turbidity, Tellus, XVI, 64-75, 1964.

Brewer, A. W., A replacement for the Dobson Spectrophotometer?, Pure Appl. Geophys., 106-108, 919-927, 1973.

Bridgman, H. A., Direct visible spectra and aerosol optical depths at urban and rural locations during summer of 1975 at Milwaukee, Solar Energy, 21, 139-148, 1978.

Cachorro, V. E., M. J. Gonzalez, A. M. de Frutos, and J. L. Casanova, Fitting Angstrom's formula to spectrally resolved aerosol optical thickness, Atmos. Env., 23, 265-270, 1989.

Cachorro, V. E., P. Durn, and A. M. de Frutos, Retrieval of vertical ozone content using the Chappuis band with high spectral resolution solar radiation measurements, Geophys. Res. Letters, 23, 3325-3328, 1996

Cebula, R. P., G. O. Thuillier, M. E. Vanhoosier, E. Hilsenrath, M. Herse, G. E. Brueckner, and P. C. Simon, Observations of the solar irradiance in the 200-350 nm interval during the ATLAS-1 mission; a comparison among three sets of measurements-SSBUV, SOLSPEC, and SUSIM, Geophys. Res. Letters, 23, 2289-2292, 1996.

Eck, T. F., B. N. Holben, J. S. Reid, O. Dubovik, A. Smirnov, N. T. O’Neill, I. Slutsker, and S. Kinne, Wavelength dependence of the optical depth of biomass burning, urban, and desert dust aerosols, J. Geophys. Res., 104, 31,333-31,349, 1999.

Fioletov, V. E., J. B. Kerr, D. I. Wardle, and E. Wo, Correction of stray light for the brewer single monochromator, Proceedings of the $2000 \mathrm{AGU}$ Spring Meeting, 369-370, 2000.

Fröhlich, C. G., and E. Shaw, New determination of Rayleigh scattering in the terrestrial atmosphere, App. Optics, 19,1773-1775, 1980.
Goldsmith, J. R., and L. T. Friberg, Effects of Air Pollution on Human Health, in Air Pollution, edited by A. C. Stern, volume II, Academic Press Inc., New York, 1977.

Holben, B. N., A. Setzer, T. F. Eck, A. Pereira, and I. Slutsker, Effect of dry-season biomass burning on Amazon basin aerosol concentrations and optical properties, 1992-1994, J. Geophys. Res., 101, 19,465-19,481, 1996.

Jacovides, C. P., M. D. Stevens, and D. N. Asimakopoulos, Spectral solar irradiance and some optical properties for various polluted atmospheres, Solar Energy, 69, 215-227, 2000.

Kaufman, Y. J., et al., Smoke, Cloud and Radiation-Brazil (SCAR B) Experiment, J. Geophys. Res., 103, 31,783-31,808, 1998.

Kaye, J. A., and T. L. Miller, The ATLAS series of shuttle missions, Geophys. Res. Letters, 23(17), 2285-2288, 1996.

King, M. D., S.-C. Tsay, S. A. Ackerman, and N. F. Larsen, Discriminating heavy aerosol, clouds, and fires during SCAR-B: Application of airborne multispectral MAS data, J. Geophys. Res., 103, 31,989-31,999, 1998.

Kirchhoff, V. W. J. H., A. A. Silva, C. A. Costa, N. P. Leme, H. G. Pavão, and F. Zaratti, UV-B Optical Thickness Observations of the Atmosphere, J. Geophys. Res., 106, 2963-2973, 2001.

Lee, Y.-N., et al., Atmospheric chemistry and distribution of formaldehyde and several multioxygenated carbonyl compounds during the 1995 Nashville/Middle Tennessee ozone study, J. Geophys. Res., 103, 22,44922,462, 1998.

Levine, J. S., The Fhotochemistry of the Early Atmosphere, in The Photochemistry of Atmospheres, edited by J. S. Levine, Academic Press Inc., New York, 1985.

Marenco, F., V. Santacesaria, A. F. Bais, D. Balis, A. di Sarra, A. Papayannis, and C. Zerefos, Optical properties of tropospheric aerosols determined by lidar and spectrophotometric measurements (Photochemical Activity and Solar Ultraviolet Radiation Campaign), App. Optics, 36, 6875-6886, 1997.

McGee, T. J., and J. Burris Jr., $\mathrm{SO}_{2}$ absorption cross sections in the near uv, J. Quant. Spectrosc. Radiat. Transfer., 37, 165-182, 1987.

Molina, L. T., and M. J. Molina, Absolute absorption cross sections of ozone in the 185 to $350 \mathrm{~nm}$ wavelengths range, Journal of Geophysical Research, 91, 14,501-14,508, 1986.

Palmer, P. I., D. J. Jacob, K. Chance, R. V. Martin, R. J. D. Spurr, T. P. Kurosu, I. Bey, R. Yantosca, A. Fiore, and Q. Li, Air mass factor formulation for spectroscopic measurements from satellites: Applications to formaldehyde retrievals from the global ozone monitoring experiment, Journal of Geophysical Research, 106, 14,539-14,550, 2001.

Pitts, B. J. F., and J. N. Pitts Jr., Atmospheric Chemistry: Fundamentals and Experimental Techniques, 1028 pp., John Wiley and Sons, New York, 1986.

Ross, J. L., P. V. Hobbs, and B. Holben, Direct radiative closure experiments on smoke from biomass burning in Brazil, in SCAR B proceedings, edited by V. W. J. H. Kirchhoff, pp. 177-182, Transtec Editorial, São José dos Campos, 1997.

Ross, J. L., P. V. Hobbs, and B. Holben, Radiative characteristics of regional hazes dominated by smoke from biomass burning in Brazil: Closure tests and direct radiative forcing, J. Geophys. Res., 103, 31,925-31,941, 1998.

Seinfeld, J. H., Atmospheric Chemistry and Physics of Air Pollution, 738 pp., John Wiley and Sons, New York, 1986.

Stolarski, R. S., The Antarctic Ozone Hole, Scientific American, 258, $20-$ 26, 1988 .

Teillet, F. M., Rayleigh optical depth comparisons from various sources, App. Optics, 29, 1897-1900, 1990.

Urbach, F., Geographic pathology of skin cancer, in The biologic effects of ultraviolet radiation, with emphasis on the skin, edited by F. Urbach, pp. 635-650, Pergamon Press, Oxford, 1969.

Warneck, P., Chemistry of the Natural Atmosphere, 757 pp., Academic Press Inc., Boston, 1988.

V. W. J. H. Kirchhoff, Instituto Nacional de Pesquisas Espaciais, 12201970 São José dos Campos, SP Brasil. (kir@dge.inpe.br)

A. A. Silva, Pontifícia Universidade Católica de Minas Gerais, Belo Horizonte, MG, Brasil.

D. K. Pinheiro, Universidade Federal de Santa Maria, RS, DTPI/ LACESM, Santa Maria, Brasil. 